\title{
Communicating sexual health messages: young adults and the female condom
}

This article was published in the following Dove Press journal:

Open Access Journal of Contraception

30 June 2014

Number of times this article has been viewed

\section{Charla Markham Shaw Karishma Chatterjee \\ Department of Communication, University of Texas at Arlington, Arlington, Texas, USA}

Correspondence: Charla Markham Shaw Box 19107, I 18 Fine Arts Building, Department of Communication, University of Texas at Arlington, Arlington, Texas 76019, USA

Tel + I 8172722678

Fax + I 8172722732

Email markham@uta.edu
Purpose: This study examined how young adult college men and women (18 to 24 years of age) viewed the female condom, in terms of its viability as a technology to be used for protection against sexually transmitted infections (STIs) and unplanned pregnancies.

Patients and methods: Information sessions led by same-sex peer educators were conducted with 55 male and 94 female participants in same-sex, small groups, followed by completion of anonymous online surveys, during Spring 2013, at a large public university in the southwestern United States.

Results: Using a grounded theory approach, the core characteristics of the $\mathrm{FC} 2^{\circledR}$ female condom found to be important to the female participants were its design, lack of side effects, protection, and convenience; the male participants focused on the protection and design elements.

Conclusion: Message-design implications for health promotion initiatives and practical implications for health practitioners were discussed.

Keywords: diffusion of innovation, STI prevention, pregnancy prevention, contraception

\section{Introduction}

Sexually active teens and young adults, as compared with older adults, encounter many sexual health risks. They account for nearly half of the new sexually transmitted infections (STIs) in the USA, despite constituting only $25 \%$ of the sexually active population. ${ }^{1}$ If not diagnosed and treated in a timely manner, the consequences of STIs are often worse for young women and may include pelvic inflammatory disease, pregnancy complications, and infertility. ${ }^{1}$ In addition to issues related to STIs, young adult women may also experience unplanned pregnancies. Approximately $18 \%$ of women who have abortions in the USA are teens, and 33\% of women who have abortions are between the ages of 20 and $24 .^{2}$ Use of barrier methods (male condom [MC] and female condom [FC]) is the only way for sexually active women to protect themselves from both STIs and unplanned pregnancies. MC usage is often a male prerogative, and women face challenges in negotiating male condom use, ${ }^{3}$ despite this, the $\mathrm{FC}^{\circledR}{ }^{\circledR}$ Female Condom ${ }^{4}$ (Female Health Company, Chicago, IL, USA) the only woman-initiated barrier method, is relatively unknown to many sexually active young adults. ${ }^{5}$ While there is research focused on FCs in the context of sex work ${ }^{6}$ and in the context of older sexually active adults, ${ }^{7}$ to date, there has been no study that examined how college-age young adults view the FC as a method for preventing STIs and unplanned pregnancies.

The goals of this study were twofold: 1) to identify the characteristics of the FC that are important to young adults and 2) to identify how young adults view the 
FC as a method of protection against STIs and unplanned pregnancies. This was accomplished through same-sex peer information sessions about the FC at a large public university in the southwestern USA, followed by an anonymous online survey.

\section{Literature review}

\section{Female condom}

Introduced by the Female Health Company in 1993, the first version of the FC, Reality ${ }^{\circledR}$, was relatively unknown in the USA, due to a variety of reasons, such as mixed or negative portrayals in the media, ${ }^{8}$ lack of community-level availability, ${ }^{7}$ and inadequate knowledge and subsequent lack of promotion by health care providers. ${ }^{9}$ In addition to evidence of its efficacy in preventing STIs and unplanned pregnancies, ${ }^{10-12}$ acceptability and usability studies suggest that the FC, as a female-initiated method of human immunodeficiency virus (HIV)/STI protection, is supported by many men and women. ${ }^{9}$ Latka et al ${ }^{13}$ found that 15 - to 20 -year-old adolescents (who had been pregnant) valued the FC's effectiveness, lack of side effects, and over-the-counter availability. The second version of the FC, FC2, was approved by the US Food and Drug Administration (FDA) in 2009. ${ }^{14}$ The FC2 appears to be gaining momentum, albeit in selective cities, such as San Francisco, Chicago, Washington DC, and New York, due to the promotion of this device by the respective city health departments. ${ }^{15}$ Given the documented lack of information about this device among most communities in the US, ${ }^{7,9}$ we examined how US college men and women aged 18 to 24 years viewed the FC. According to Bull et al, ${ }^{5}$ “ .... literature cannot tell you about specific preferences of a target audience, and that program success hinges on input from participants". Any successful health educational effort to increase awareness of the FC would, thus, need the perspective of the target audience, including both men and women, to "communicate meaningfully and effectively the ways they can control and protect their health". 8

\section{Diffusion of Innovation}

Diffusion of Innovation ${ }^{16,17}$ (DOI) served as the theoretical framework that guided the present study. DOI proposes that an innovation spreads through a social system via networks of communication, from the source to the adopter. ${ }^{16}$ Wejnert ${ }^{17}$ integrated the research in DOI to offer three variables as affecting an actor's decision to adopt an innovation: characteristics of innovations; characteristics of innovators; and environmental context. Weighing the benefits and costs of a device has been considered a characteristic of an innovation. ${ }^{17}$ Costs refer to the monetary and nonmonetary direct and indirect costs associated with an innovation. Research indicates that indirect costs are often not easily identifiable, but they can moderate the rate of adoption. ${ }^{17}$ For example, social cost is an indirect cost that may come in the form of ridicule from a partner for using a form of contraception that has not been socially approved. ${ }^{18}$ The monetary cost of the device is a direct cost; the cost of a pack of three FC2 FCs ranges between $\$ 3.13$ and $\$ 5.99 .{ }^{4}$ The price of the original FC, Reality, was up to $\$ 15.00$ for a packet of three. Wejnert ${ }^{17}$ suggests "direct and indirect costs of innovation often inhibit adoption, especially when costs exceed an actor's resource potential".

According to the latest National Survey of Family Growth 2006-2008 ${ }^{19}$ conducted by the National Survey for Health Statistics, of the reported 13.6 million women who stopped using the pill, 64\% stopped due to attributed side effects, and $13 \%$ stopped because they were worried about side effects. Some of the main reasons for stopping use of the MC included partners did not like using condoms (41\%) and decreased sexual pleasure (40\%). ${ }^{19}$ According to the $\mathrm{FHC},{ }^{20}$ FC2 has no documented side effects and as compared with latex MCs, it does not cause allergies. Additionally, the FC2 can be used when male partners do not want to use the MC. ${ }^{19}$ Although a barrier method, the FC2's material conducts heat, its design can stimulate both partners, and the FC2 can be inserted before the onset of sexual activity. ${ }^{4}$ Given the characteristics of the FC2 as compared with the pill and the male condom, it is possible that college-age adults may find the device appealing.

In addition to the characteristics of the innovation, Wejnert ${ }^{17}$ identified six actor characteristics that influence the diffusion process, such as societal entity, familiarity with the innovation, status, socioeconomics, relative position in social networks, and personal characteristics. Two of the characteristics, familiarity with the innovation and socioeconomics, are particularly relevant to our study. There are many factors that can increase familiarity with an innovation; Rogers ${ }^{16}$ found that information that is shared by peers in one's network "has more weight than information obtained from objective sources, such as from the media or from scientific evaluations of an innovation". Hence, peers (an undergraduate male and a female student) led the information sessions in same sex groups in our study. The second characteristic, socioeconomics, includes economic and sociodemographic variables, such as education levels and economic well-being. Education levels of women in the USA are correlated with contraceptive pill use such that the percentage of women using oral contraception 
aged 22 to 44 years increases from 10\% for non-high school graduates to $18 \%$ for high school graduates, $23 \%$ for those with some college, and $35 \%$ for college graduates. Given the reasons women stop using hormonal and barrier methods and given their demographics, college-age women could be potential adopters of the FC. ${ }^{19}$

In terms of the third variable, environmental contexts, Wejnert ${ }^{17}$ argues that the cultural mores of a social system can also influence an innovation's adoption. This includes belief systems, consisting of values, norms, religion, language, and ideology. In the context of the FC, although some college-age women may consider the FC2 to be empowering as they can initiate sexual protection, the FC as a social artifact could potentially challenge social norms of gender and sexual practices. This is considered to be one of several reasons why the FC1 was not successful in the USA in the 90 s. ${ }^{9}$ The male condom has existed in various forms for hundreds of years; in contrast, as Scarce ${ }^{21}$ notes, "Reality was the first sexual barrier device to radically depart from the traditional design of a sheath worn on the penis." Scarce ${ }^{21}$ argues that by offering women the simultaneous ability to prevent unplanned pregnancy and STIs, the FC potentially offers “... to endow its user with greater gender equality by balancing the scales of control between insertive and receptive partners of heterosexual intercourse". In many heterosexual relationships, contraception decisions are often negotiated, and male partner resistance is linked to women's decisions to stop using FCs. ${ }^{9}$ Given that power in relationships influences contraceptive use, one cannot overlook the norms of sexual practices that may be challenged by this technology. Hence, is also important to take into consideration men's perspective of the FC2, if the device is to be successfully used by young adult women in heterosexual relationships.

In summary, DOI suggests that potential adopters of an innovation weigh the benefits and costs of an existing technology with the innovation. The FC2, unlike hormonal contraception, does not have side effects. As compared with the male condom, it may offer pleasure to both partners and may be appealing to men and women who embrace the notion of a female-initiated barrier method. Although the FC2 is priced lower than the $\mathrm{FC1}$, we do not know whether this price is feasible for sexually active young adults. The FC2 may be viewed as an option to existing contraceptive methods, especially given the reasons why some of them stop using male condoms and hormonal contraception.

In an effort to identify characteristics attributed to and perceptions of the FC technology, we asked the following questions:
- What characteristics of the FC are important to young adults (18-24 years)?

- How do young adults view the FC as a means of protection against STIs?

- How do young adults view the FC as a means of protection against unplanned pregnancies?

\section{Material and methods Participants}

Following Institutional Review Board approval, we recruited participants from lower-division communication courses at a large southwestern US university through classroom visits. The eligibility criterion was that the participants had to be between the ages of 18-24 years. All participants received extra credit for their participation, as deemed appropriate by the professor of the course in which they volunteered. Participation was voluntary, and alternative options for extra credit were provided. Of the 500 potential participants, the response rates for the male and female samples were approximately $28.9 \%$ and $30.3 \%$, respectively. The sample included 55 men and 94 women. Participants ranged in age from 18 to 24 years with an average age of 21 years. Among the sample, 53 participants self-identified as Caucasian/White, 40 as African American/Black, 18 as Asian/Asian American, 33 as Latino/Hispanic, two as Middle Eastern, two as Mixed, and one as Hawaiian/Native American.

All participants indicated type(s) of contraception currently used, as part of the online survey (Table 1). Participants were also asked: "Had you heard of the female condom before today's presentation?" and "Have you ever used the female condom?" More males (74.55\%) than females $(65.59 \%)$ had reportedly heard of the FC before the peer education session; from this subsample of participants, no one reported that they had used the FC.

\section{Study design}

The present study examined how young adult college men and women (18 to 24 years of age) view the FC (FC2) in terms of its viability as a technology to be used for protection against STIs and unplanned pregnancies. The study consisted

Table I Contraception use of participants

\begin{tabular}{llll}
\hline & $\begin{array}{l}\text { Condoms } \\
\mathbf{n}(\%)\end{array}$ & $\begin{array}{l}\text { Birth control } \\
\mathbf{n}(\%)\end{array}$ & $\begin{array}{l}\text { Condoms and } \\
\text { birth control } \mathbf{n}(\%)\end{array}$ \\
\hline Males & $30(54.5 \%)$ & $2(3.6 \%)$ & 0 \\
Females & $9(9.6 \%)$ & $21(22.5 \%)$ & $7(7.5 \%)$ \\
\hline
\end{tabular}

Notes: $\mathrm{N}=55$ (males); $\mathrm{N}=93$ (females). Birth control included hormonal options, such as the pill, the patch, the ring, and the injection. Sometimes respondents did not specify the type of hormonal birth control. 
of two parts. In the first stage, male and female participants, in same-sex groups of seven to 15 participants, attended a 15-minute information session led by a same-sex peer educator, to ensure basic understanding of the device. In the second stage, immediately following the information session, participants completed an anonymous online survey, in a nearby computer lab. The survey asked questions related to perceptions of protective methods and questions specific to perceptions of the FC as a means of protection from STIs and unplanned pregnancies.

\section{Peer education sessions}

The researchers chose two undergraduate students to serve as peer educators (one male and one female). Both students were senior Communication Studies majors enrolled in advanced communication courses. The researchers trained the peer educators by providing them with the FHC resource manual "Safer is Sexy: Resource Kit for Professionals", information from the Centers for Disease Control and Prevention (CDC), and academic articles related to perceptions and use of the FC2 ${ }^{8-10}$ The peer educators were provided with an outline script, instruction, and practice in using the FC2 in a pelvic model. Peer educators practiced with the researchers and with each other as they prepared to provide consistent information and to address potential questions. Peer educators were trained to use a consistent, informative format and a conversational style in each of their sessions. In an effort to relate the issue to the study participants, the sessions opened with STI statistics and their impact on 15 - to 25 -year-olds. The FC was then introduced as one option to protect sexual health. The three major topics of the presentation were: 1) Why is the FC important (focus on sexual health)?; 2) How does the FC work (each participant given a FC2 pelvic model demonstration)?; 3) How effective is the FC (CDC and Planned Parenthood information provided)?

In the second section of the presentation, the peer educators introduced the FC by showing an unrolled male condom beside a FC2. In this way, participants could see what was for many, a new technology next to something more familiar. The peer educators then demonstrated the insertion and placement of the FC2 via a pelvic model, after first briefly identifying the location of anatomical parts, such as the cervix, vagina, pelvic bone, and uterus. Each participant was provided an unopened FC2, and after demonstrating how the FC2 is inserted, the peer educators encouraged participants to open the package and handle the device. They also encouraged participants who were interested, to try the device on the model. In the third section of the presentation, the peer educators discussed effectiveness statistics related to STIs and unplanned pregnancies. Before opening the session for questions, the peer educators presented information concerning additional design elements that had implications beyond sexual health, related to pleasure and allergies (nonlatex and oil/water lubrication), and informed the participants of cost and availability (retail and health locations).

\section{Online surveys}

Following the information sessions, participants completed an anonymous survey on Surveymonkey.com where they answered questions about contraception use, their knowledge about the FC, and their likes and dislikes regarding the FC2. Apart from the demographic questions that provided choices to pick from, participants were asked the following yes/no and open-ended questions: "Are you currently using some form of contraception?" Participants who answered "yes" were then asked: "What form of contraception are you using?" Participants who answered "no" and those who had indicated the type of contraception they were using were then asked the following questions: "Had you heard of the female condom before today's presentation?"; "Have you ever used the female condom?"; "How effective do you think the female condom would be in preventing sexually transmitted infections (STIs)?"; "How effective do you think the female condom would be in preventing an unplanned pregnancy?"; "A box of three female condoms costs approximately $\$ 5.00$. Would you be willing to pay that amount?"; "How much would you be willing to pay for a box of three?"; "What do you like about the female condom as compared to other means of birth control such as the pill or the male condom?"; "What do you dislike about the female condom as compared to other means of birth control such as the pill or the male condom?"; "What is your age?"; and "What is your race/ethnicity?"

\section{Coding}

Both researchers independently analyzed the data using grounded theory to identify emerging themes. ${ }^{22}$ We employed an iterative process of analyzing the data, to identify the categories and subcategories, and subsequently placed units of analysis into relevant, unified thematic core categories. ${ }^{23}$ A high level of agreement was reached, with differences resolved through discussion and revisit of the data.

\section{Results}

Among the participants, $39.78 \%$ of the women and 58.18\% of the men reported that they currently used contraception. 
Among the female contraceptive users, the majority (56.76\%) reported using some form of hormonal birth control, $24.32 \%$ reported using male condoms, and $18.91 \%$ reported using a combination of hormonal birth control and male condoms. Among the male contraceptive users, the majority (93.75\%) reported using male condoms, and $6.25 \%$ reported using hormonal birth control.

\section{Female condom}

Participants responded to two questions asking what they liked and disliked about the FC.

\section{Like}

Of the female responses, eleven were discarded because they lacked content (eg, "much better") or because the respondents indicated they were "not sexually active" and did not comment on the device. The remaining 83 responses revealed nine categories (Table 2). Of the male responses, eight responses were eliminated; the remaining 45 responses revealed nine categories (Table 3 ).

\section{Dislike}

Of the female responses, four were eliminated; the remaining 90 responses revealed seven core categories (Table 4). Of the male responses, seven were eliminated; the remaining 48 responses revealed six core categories (Table 5).

\section{STIs and unplanned pregnancies}

Participants responded to the open-ended question, "How effective do you think the female condom would be in

Table 2 Characteristics of $\mathrm{FC} 2^{\circledR}$ liked by female participants

\begin{tabular}{|c|c|c|}
\hline Core category & Focus of responses & n (\%) \\
\hline Design & $\begin{array}{l}\text { Durable, lubricated, pleasurable to } \\
\text { both, nonrestrictive, tailored to } \\
\text { women's bodies, thin material }\end{array}$ & $43(51.8 \%)$ \\
\hline No side effects & $\begin{array}{l}\text { "Not cause side effects such as mood } \\
\text { swings or weight gain" }\end{array}$ & $29(34.9 \%)$ \\
\hline Protection & $\begin{array}{l}\text { Skin coverage, STI, and pregnancy } \\
\text { prevention }\end{array}$ & $28(33.7 \%)$ \\
\hline Convenience & $\begin{array}{l}\text { "No hassle" in remembering, } \\
\text { preinserted, "use it when you want" }\end{array}$ & $26(31.3 \%)$ \\
\hline Power/control & "Puts female in control" & $14(16.8 \%)$ \\
\hline Comfortable & "It doesn't look uncomfortable" & 7 (8.4\%) \\
\hline Ease of use & $\begin{array}{l}\text { "Like the easiness of using and } \\
\text { removing the condom" }\end{array}$ & $6(7.2 \%)$ \\
\hline $\begin{array}{l}\text { Alternative to } \\
\text { existing options }\end{array}$ & "Adds another option for the couple" & $4(4.8 \%)$ \\
\hline Novelty & "It's a great idea and worth a try" & $4(4.8 \%)$ \\
\hline
\end{tabular}

Notes: The percentages do not add up to 100 as some respondents provided multiple characteristics they liked. $\mathrm{FC} 2^{\circledR}$; Female Health Company, Chicago, IL, USA.

Abbreviation: STI, sexually transmitted infection.
Table 3 Characteristics of $\mathrm{FC} 2^{\circledR}$ liked by male participants

\begin{tabular}{|c|c|c|}
\hline $\begin{array}{l}\text { Core } \\
\text { category }\end{array}$ & Focus of responses & n (\%) \\
\hline Protection & $\begin{array}{l}\text { Skin coverage, STI and pregnancy } \\
\text { prevention }\end{array}$ & $21(44.6 \%)$ \\
\hline Design & $\begin{array}{l}\text { Nonconstricting/comfortable, pleasure } \\
\text { for both, fits to woman/responds to } \\
\text { body heat, visible, durable }\end{array}$ & $12(25.5 \%)$ \\
\hline $\begin{array}{l}\text { No } \\
\text { responsibility }\end{array}$ & $\begin{array}{l}\text { "I don't have to worry about wearing } \\
\text { a condom" } \\
\text { "It takes the burden off of the male" }\end{array}$ & $6(12.7 \%)$ \\
\hline Convenience & $\begin{array}{l}\text { Preinsertion/ready/no "mood killer", } \\
\text { no pill for woman to remember }\end{array}$ & $6(12.7 \%)$ \\
\hline No side effects & Chemical (pill), latex allergy & $6(12.7 \%)$ \\
\hline Ease of use & "easy to apply" & $4(8.5 \%)$ \\
\hline Cost effective & When compared with the pill & $4(8.5 \%)$ \\
\hline Novelty & "Interesting" and "fun" & $2(4.2 \%)$ \\
\hline $\begin{array}{l}\text { Female power/ } \\
\text { control }\end{array}$ & $\begin{array}{l}\text { "It gives the women more power and } \\
\text { control to protect their bodies" }\end{array}$ & $2(4.2 \%)$ \\
\hline
\end{tabular}

Notes: The percentages do not add up to 100 as some respondents provided multiple characteristics they liked. $\mathrm{FC} 2^{\circledR}$; Female Health Company, Chicago, IL, USA. Abbreviation: STI, sexually transmitted infection.

preventing sexually transmitted infections (STIs)?" Of the female responses, four were eliminated; 83 indicated that they felt the FC would be effective in preventing STIs, and six felt that it would be ineffective. Of the male responses, nine were eliminated, and 46 indicated that they felt the FC would be effective in preventing STIs.

Participants responded to the open-ended question, "How effective do you think the female condom would be in preventing unplanned pregnancies?" Of the 93 female participants, 73 felt that the FC would be effective in preventing unplanned pregnancies, five felt that the $\mathrm{FC}$ would be ineffective, and 15 answers were eliminated. Of the 55 male participants, 45 felt that the FC would be effective in preventing unplanned pregnancies, one felt that the FC would be ineffective, and nine answers were eliminated.

Table 4 Characteristics of $\mathrm{FC} 2{ }^{\circledR}$ disliked by female participants

\begin{tabular}{|c|c|c|}
\hline Core category & Focus of responses & n (\%) \\
\hline Design & $\begin{array}{l}\text { "Large size" and appearance, } \\
\text { visible to partner }\end{array}$ & $30(33.3 \%)$ \\
\hline Insertion & Difficulty/fear of insertion & $23(25.5 \%)$ \\
\hline Uncomfortable & Get stuck, hurt, slip & $15(16.6 \%)$ \\
\hline Dislike nothing & Found nothing to dislike & $13(14.4 \%)$ \\
\hline Inconvenient & Not spontaneous, nondiscrete & $9(10 \%)$ \\
\hline Nonnormative & $\begin{array}{l}\text { Not widely known, not widely } \\
\text { available }\end{array}$ & 7 (7.7\%) \\
\hline Price & $\begin{array}{l}\text { More expensive as compared } \\
\text { with male condom }\end{array}$ & $6(6.6 \%)$ \\
\hline
\end{tabular}

Notes: The percentages do not add up to 100 as some respondents provided multiple characteristics they disliked. $\mathrm{FC} 2^{\circledR}$; Female Health Company, Chicago, IL, USA. 
Table 5 Characteristics of $\mathrm{FC}^{\circledR}{ }^{\circledR}$ disliked by male participants

\begin{tabular}{|c|c|c|}
\hline Core category & Focus of responses & n (\%) \\
\hline Design & $\begin{array}{l}\text { Large size, appearance, less skin-to- } \\
\text { skin contact }\end{array}$ & $17(35.4 \%)$ \\
\hline Dislike nothing & "I have no dislikes" & $12(25 \%)$ \\
\hline \multirow[t]{2}{*}{ Nonnormative } & “Not widely known” & $9(18.75 \%)$ \\
\hline & "Not found in many stores" & \\
\hline Price & As compared with the male condom & $6(12.5 \%)$ \\
\hline Inconvenient & Not spontaneous, nondiscrete & $6(12.5 \%)$ \\
\hline Insertion & Difficulty of insertion & $3(6.25 \%)$ \\
\hline
\end{tabular}

Notes: The percentages do not add up to 100 as some respondents provided multiple characteristics they disliked. FC2 ${ }^{\circledR}$; Female Health Company, Chicago, IL, USA.

\section{Cost}

A majority of female participants $(76.3 \%[n=71])$ reported that they would be willing to pay approximately $\$ 5.00$ for a box of three FCs, whereas the remaining reported they would pay less than $\$ 5.00$. As was the case with the female responses, $76.3 \%(\mathrm{n}=42)$ of the male participants reported that they would be willing to pay $\$ 5.00$ for a box of three FCs.

\section{Discussion}

The aim of this study was to learn about the characteristics of the FC that are important to young college adults and to identify how they view the FC as a method of protection against STIs and unplanned pregnancies. The findings suggest that characteristics such as design, lack of side effects, protection, and convenience were important to the majority of the college women. For college men, all of the above were important, along with the idea that the FC would take the burden of protection off their shoulders. Although the majority of the college men and women who participated in this study indicated that they had heard of the FC, few had seen one. Being familiar with an innovation has been identified as influencing the diffusion process. ${ }^{17}$ Seeing and touching the FC was a key element in this study. It gave the participants an opportunity to, not only get familiar with the FC but also, evaluate it by comparing it with other contraceptives. Over half the women and one-fourth of the men liked the design as a characteristic of the FC. Both men and women liked the design because it "fits to the woman", "is more lubricated than a male condom", is "durable", "is stimulating for both partners", and unlike the male condom, would not be restrictive. Finally, a few of the men noted that they physically like seeing birth control as it takes guesswork out of the relational equation.

A lack of side effects was the second most listed "liked" characteristic mentioned by women. The primary specific side effect mentioned, in relation to the birth control pill, was the lack of chemicals; other respondents mentioned that the FC would help them avoid "gaining weight" and "suffering from nausea". For women, who must make the decision related to use of the birth control pill, the lack of side effects associated with the $\mathrm{FC}$ was a characteristic that was named slightly more often than was the third thematic category of protection. Given that the National Survey of Family Growth suggested that $80 \%$ of 13.5 million women stopped using the pill due to attributed side effects or worry about side effects, ${ }^{20}$ this is a salient characteristic that must be highlighted in educational efforts as it may override women's desire to protect themselves from STIs and unplanned pregnancies.

Protection, the most often mentioned liked characteristic for men, ranked third for women. Both men and women liked that the $\mathrm{FC}$ provides more protection from skin-to-skin contact when compared with the male condom and offers protection from both STIs and unplanned pregnancies as compared with the pill. The portion of the instruction that focused on reduced skin-to-skin contact and potential for transmission of STIs clearly resonated with the audience of college men and women. This characteristic is one that should be clearly communicated with potential adopters, in health educational messaging about the device.

It makes sense that men would view protection as the most liked characteristic and elements of the design, second, as men would not have to place the device on or in their bodies. However, in their responses, women were primarily focused on design elements, suggesting that design elements, such as lubrication, durability, and thin material, are salient to women and need to be highlighted in educational messaging about the benefits of the FC.

A fourth characteristic women liked was the convenience of the FC. This theme was primarily seen in relation to the birth control pill, "With the pill you have to actually remember to take it, whereas the female condom you can just use", and "You can put it $[\mathrm{FC}]$ in before the date and leave it until something happens."

Both men and women mentioned a more minor theme, female power and control, as a characteristic they liked about the FC: "It puts the female in control." One male respondent said, "In a society dominated by males, putting the decision for birth control in the hands of women (who have more risk during sexual relations) is an empowering action." We juxtapose this characteristic of the FC with the theme of no responsibility that was unique to men. When asked what they liked about the FC, this theme was seen in comments 
such as "I don't have to worry about wearing a condom", "It takes the burden off of the male", and "I don't have to worry about carrying a condom". These findings suggest that some college-age men and women, as compared with other population groups, may be more accepting of the FC as a social artifact that allows for gender equality in heterosexual intercourse.

While liking these design elements, the primary "dislike" for both male and female respondents was also design elements - the FC's size and appearance: "it is too large" and "think it would look weird during sex". Choi et al ${ }^{24}$ also found that two-thirds of their respondents considered the size and appearance to be an obstacle to use. In the present study, a small number of women worried that "it will make my partner nervous because of the way it looks" and "the male partner has to look at it." Interestingly, an equivalent portion of the male respondents indicated that they liked that they could see the FC as it gave them some reassurance in terms of birth control. Although some men did indicate that it is was "strange looking", one went on to say that this "is probably what they thought of when the condom was introduced". Instead of skirting the issue of its appearance, educational messaging should acknowledge that this looks different but point to ideas indicated by some of the male respondents, such as piece of mind provided when seeing it and, as indicated by both men and women, the novelty and fun of "trying something different" and the pleasure potential that this difference can provide.

A considerable number of the women were particularly concerned that the FC would be too big for them, and a number of men also indicated that the $\mathrm{FC}$ was large. In hindsight, although the peer educators showed the FC alongside the male condom as a point of reference, that brief visual was not sufficient. Each participant should have received both a male condom and FC and been directed to compare them. The pelvic model, made of clear plastic, did not replicate the adhesion of the FC to the body; as a result, it hung loosely inside and did not provide an accurate image of how the FC works within the female body. It might be more useful to work with a two- dimensional pelvic model (side view) and hold the $\mathrm{FC}$ in place when demonstrating insertion or a model to which the FC would cling.

In addition, as the theme of insertion was the second most disliked characteristic of the FC for women, it would be important to compare insertion to something more familiar (such as a tampon). Women who indicated insertion as a disliked characteristic were focused on difficulty of insertion or indicated that they were "scared" to put it in. Relating back to memories of first experiences with tampons may provide a frame of reference for women with this new technology. This too, would address the uncomfortable theme, the third most disliked characteristic, in relation to the concern that the FC might get stuck or slip during use.

Interestingly, both men and women indicated that they disliked nothing about the FC. In fact, it was the second largest response for men. As a small number of women voiced concern in this study about partner acceptance, understanding how partners may respond is important. In this study, one-fourth of the men indicated that they disliked nothing about the FC. As Rogers ${ }^{16}$ contends, information about an innovation must spread to the adopter. In this case, the adopter may be negotiating use of the technology with a partner and, hence, this is a dual adoption. Perceptions of partner acceptance of the FC must be informed and, as an indirect cost, ${ }^{17}$ may moderate the successful adoption of this new technology. Including men in educational sessions related to female health is important in making them informed partners who can effectively communicate their perceptions.

A third disliked characteristic for men, and a more minor theme for women, was that the FC is nonnormative: "It is not widely known", and "It's not found in many stores". As one male respondent put it, "My dislike for the female condom is more based on being less culturally relevant than the male condom. You hear less about them therefore it must not be 'as good"'. This harkens back to the suggestion, by Choi et al, ${ }^{24}$ Penman-Aguilar et al, ${ }^{25}$ Mantell et al, ${ }^{9}$ and others, that in those cultures where women are not the sole decision makers related to contraception, messages should include the male partner. As Weeks et $\mathrm{al}^{7}$ suggest, the FC should be "readily available and commonly known as the $\mathrm{MC}$, so that when it is needed or desired, both women and men can access and incorporate it into their sexual practices".

Both men and women also identified the FC as inconvenient, when asked what characteristics they disliked. Some of the women felt that the FC would be "a hassle to deal with every time I have sex" and would be too "big to fit in a purse." A couple of the men also indicated, "I'm not sure how the female counterpart will like carrying something that large." Although the packaging for the FC is more than twice as large as the male condom, it is as thin and would easily slip into a purse or wallet. It is clear that, as with the size of the FC itself, more needs to be done with the package during the information sessions, to demonstrate its size relative to a small wristlet, wallet, or purse. 
Although a minor disliked characteristic for both men and women, the issue of price was apparent. Nearly threefourths of female and male participants reported that they would be willing to pay the average $\$ 5.00$ for a box of three FCs. Although the price for the FC2 is significantly lower than that of the FC1, a FC costs roughly twice as much as a male condom. Though a minor disliked characteristic in the present study, direct and indirect costs can inhibit an innovation's adoption, especially when the costs exceed an actor's resource potential. ${ }^{17}$ Therefore, in communicating about price during the information session, it may be important to use a cost-benefit analysis strategy. When comparing the price of a male condom with a FC, benefits that resonated with the respondents should be included: design elements (durability, lubrication, nonrestricting, pleasurable, and visible); protection (greater coverage and STI protection); and convenience (preinsertion).

The majority of the female and male respondents indicated that they believed that the FC would be efficacious in providing protection from STIs and unplanned pregnancies, if used correctly. The explanations that participants provided were similar to the design (durable) and protective (less skinto-skin) characteristics discussed previously. Some of the concerns expressed by those participants who did not think the FC would be effective were related inexperience with the device and are similar to concerns with the male condom, such as ripping or tearing.

In addition to components of message design, the results of this study suggest that health care providers should provide clients opportunities for direct experience with the FC as a new technology. A number of participants asked whether they could take a FC with them to try. Providing samples at no cost would likely encourage women and men to become more familiar and comfortable with the technology. Research indicates that knowledge about using the FC is positively predictive of FC use. ${ }^{26}$

\section{Conclusion}

There are four main limitations of this study. First, the convenience sample was not representative of all college campuses; therefore, the findings cannot be generalized. Second, the male sample was much smaller than the female sample, and the findings should be interpreted with this in mind. Third, it is possible that doing a "post" survey after the education session may have biased some of the participant responses; however, previous research used a similar study design to examine which characteristics of the FC are valued by teenagers. ${ }^{13}$ Fourth, participant responses were based on observations, demonstrations, and insertion of the device into a plastic model. Actual use and experience with the FC may have led to different responses. Future studies should attempt to recruit a random sample and recruit more men, in order to be able to make generalizations. Future studies should also include a "pre" survey before the education sessions, to reduce potential bias, and participants should be given an opportunity to use or have experience with the device. Overall, our sample was quite diverse and reasonable given the qualitative nature of the study.

Future research should be conducted in other areas with college men and women across the USA. Given previous research that correlates levels of education with oral contraception use, ${ }^{19}$ research with populations of this age who are not college educated may reveal different results, with implications for other audiences. Relevant communication, targeted to its audience and based on information about the potential adopters of a new health technology, such as the $\mathrm{FC}$, can serve to provide pertinent information that may go beyond the workings of the technology.

\section{Disclosure}

The authors report no conflicts of interest in this work.

\section{References}

1. Centers for Disease Control and Prevention. CDC Fact Sheet: Incidence, Prevalence, and Cost of Sexually Transmitted Infections in the United States. Atlanta, GA: Centers for Disease Control and Prevention; 2013. Available from: http://www.cdc.gov/std/stats/STI-Estimates-Fact-SheetFeb-2013.pdf. Accessed September 1, 2013.

2. Kaiser Family Foundation. Sexual Health of Adolescents and Young Adults in the United States. Mento Park, CA: Kaiser Family Foundation; 2013. Available from: http://kaiserfamilyfoundation.files.wordpress. com/2013/04/3040-06.pdf. Accessed March 11, 2014.

3. Raiford JL, Diclemente RJ, Wingood GM. Effects of fear of abuse and possible STI acquisition on the sexual behavior of young African American women. Am J Public Health. 2009;99(6): $1067-1071$.

4. fc2.us.com [homepage on the Internet]. FAQS. Female Health Company; 2013 [cited August 1, 2013]. Available from: http://www.fc2.us.com/ faqs/. Accessed May 11, 2014.

5. Bull SS, Cohen J, Ortiz C, Evans T. The POWER campaign for promotion of female and male condoms: audience research and campaign development. Health Commun. 2002;14(4):475-491.

6. Stockman JK, Morris MD, Martinez G, et al. Prevalence and correlates of female condom use and interest among injection drug-using female sex workers in two Mexico-US border cities. AIDS Behav. 2012;16(7):1877-1886.

7. Weeks MR, Hilario H, Li J, et al. Multilevel social influences in female condom use and adoption among women in the urban United States. AIDS Patient Care STDS. 2010;24(5):297-309.

8. Chatterjee K, Markham Shaw C. Media portrayals of the female condom. J Health Commun. 2012;17(10):1138-1150.

9. Mantell JE, Dworkin SL, Exner TM, Hoffman S, Smit JA, Susser I. The promises and limitations of female-initiated methods of HIV/STI protection. Soc Sci Med. 2006;63(8):1998-2009. 
10. French PP, Latka M, Gollub EL, Rogers C, Hoover DR, Stein ZA. Useeffectiveness of the female versus male condom in preventing sexually transmitted disease in women. Sex Transm Dis. 2003;30(5):433-439.

11. Galvão LW, Oliveira LC, Díaz J, et al. Effectiveness of female and male condoms in preventing exposure to semen during vaginal intercourse: a randomized trial. Contraception. 2005;71(2):130-136.

12. Vijayakumar G, Mabude Z, Smit J, Beksinska M, Lurie M. A review of female-condom effectiveness: patterns of use and impact on protected sex acts and STI incidence. Int J STD AIDS. 2006;17(10):652-659.

13. Latka MH, Kapadia F, Fortin P. The female condom: effectiveness and convenience, not "female control," valued by US Urban adolescents. AIDS Educ Prev. 2008;20(2):160-170.

14. FC2 Female Condom [conditions of approval letter]. Rockville, MD: Food and Drug Administration; 2009. Available from: http://www.accessdata. fda.gov/cdrh_docs/pdf8/P080002a.pdf. Accessed May 11, 2014.

15. Rubin R. Female condoms are gaining ground. USA Today; March 2, 2011. Available from: http://usatoday30.usatoday.com/news/health/ medical/health/medical/womenshealth/story/2011/03/Female-condomsare-gaining-ground/44422408/1. Accessed August 1, 2013.

16. Rogers EM. Diffusion of Innovations. 4th ed. New York, NY: The Free Press; 1995.

17. Wejnert B. Integrating models of diffusion of innovations: a conceptual framework. Annu Rev Sociol. 2002;28:297-326.

18. Rosero-Bixby L, Casterline JB. Interaction diffusion and fertility transition in Costa Rica. Soc Forces. 1994;73(2):435-462.
19. Mosher WD, Jones J. Use of contraception in the United States: 1982-2008. Vital Health Stat 23. 2010;(29):1-44.

20. Female Health Company. Safer is Sexy. Resource Kit for Professionals Promoting Use of the FC2 Female Condom ${ }^{\circledR}$. Chicago, IL: Female Health Company. Available from: http://www.fc2femalecondom.com/training/ pdfs/materials/Manuals/safer_is_sexy_resource_kit_for_professionals. pdf. Accessed January 15, 2013.

21. Scarce M. Anal sex and the female condom: Are gay men getting a bum wrap? In: Eglash R, Croissant J, Di Chiro G, Fouché R, editors. Appropriating Technology: Vernacular Science and Social Power. Minneapolis, MN: University of Minnesota Press; 2004:63-78.

22. Strauss A, Corbin J. Basics of Qualitative Research: Techniques and Procedures for Developing Grounded Theory. 2nd ed. Thousand Oaks, CA: Sage Publications; 1998.

23. Glaser BG, Strauss A. The Discovery of Grounded Theory: Strategies for Qualitative Research. Piscataway, NJ: Aldine Transaction; 1967.

24. Choi KH, Roberts KJ, Gomez C, Grinstead O. Facilitators and barriers to use of the female condom: qualitative interviews with women of diverse ethnicity. Women Health. 1999;30(1):53-70.

25. Penman-Aguilar A, Hall J, Artz L, et al. Presenting the female condom to men: a dyadic analysis of effect of the woman's approach. Women Health. 2002;35(1):37-51.

26. Holmes L, Ogungbade GO, Ward DD, et al. Potential markers of female condom use among inner city African-American women. AIDS Care. 2008;20(4):470-477.
Open Access Journal of Contraception

\section{Publish your work in this journal}

Open Access Journal of Contraception is an international, peerreviewed, open access, online journal, publishing original research, reports, reviews and commentaries on all areas of contraception. In addition to clinical research, demographics and health-related aspects, the journal welcomes new findings in animal and preclinical studies

\section{Dovepress}

relating to understanding the biological mechanisms and practical development of new contraceptive agents. The manuscript management system is completely online and includes a very quick and fair peer-review system. Visit http://www.dovepress.com/testimonials.php to read real quotes from published authors. 